A 103

船舶抵抗低減のための気泡道入装置に関する研究 曳航円柱による気液界面の変形と気泡生成に関する可視化実験一

熊谷 一郎 ${ }^{\circ}$ (北大)，中村 直哉（北大），村井 祐一（北大）

田坂 裕司（北大），武田 靖（北大）

\title{
A Towing-tank Experiment on Dynamics of Air Bubble Introducer for Drag Reduction of Ships Flow Visualization of Air Entrainment and Bubble Formation by the Flow Past a Cylinder beneath a Free Surface -
}

Ichiro Kumagai, Naoya NaKamura, Yuichi MuraI, Yuji TASAKA and Yasushi TAKEDA

\begin{abstract}
We have conducted laboratory experiments on bubble formation by the flow past a circular cylinder beneath a free surface in order to understand the mechanism of the air bubble introducer for drag reduction of ship. At large Reynolds and Froude numbers, surface deformation becomes substantial in the downstream of the cylinder and wave breaking with air entrainment occurs. The regime diagram as a function of Re and Fr numbers shows a threshold of bubble formation, which helps to improve the air bubble introducer for drag reduction of ships.
\end{abstract}

Keywords : Drag reduction, Air bubble entrainment, Free surface, Circular-cylinder, Dynamics

1. 緒 論

気泡による船舶の正味の摩摖抵抗低減は，空気をいか に効率的に船底へ導入し微小気泡を発生させるかにかか っている.我々は船底に水中翼を装着した気泡導入装置 を開発し，ほぼ大気圧のままそれらを実現することに成 功した。しかしながら，気液界面值下を通動寸る物体に よってその界面がどの程度変形し，どのように気体が液 体中に取り込まれていくのかについては良くわかってい ない，そこで我々は，最も简単な形状の 1 つである円柱 を気液界面直下において一定速度で連動させ，界面形状 p気泡発生が, Reynolds 数, Froude 数, 無次元深さに よってどのように変化するのか室内実験によって調べた。

\section{2. 実験装置·方法およびパラメータ}

\section{1 实験装置・方法}

実験装固の画像を Fig. $1 \mathrm{a}$ に示す. $0.5 \times 0.5 \times 5 \mathrm{~m}$ （長 さ）の水槽に哚さ $0.35 \mathrm{~m}$ まで水道水を満たし, 円柱 （值径 $\mathrm{d}=20 \mathrm{~mm}$, 長さ $350 \mathrm{~mm}$ ） を水面下（樑さ h) に沈めた，円柱は，その長軸を逊動方向と值交させた状 態にし，水槽と並行して設置された直動ステージにより 一定速度 $U_{0}$ で水平方向に運動させ，円柱後方にできる 気液界面の淕み量（最大深さw）を計測した(Fig. 1b). 実験の様子は，水槽脇に設置した高速度カメラ
(Photron 社製，250 frames/sec，テレセントリックレ ンズ）を用いて撮影した，水槽下部からハロゲンランプ のライトシートを照射し，水に混入させたトレーサーの 動きから流れ場を可視化した。また，気液界面からの気 体の取り込みの様子を撮影するために，円柱とともに運 動するデジタルカメラを円柱上部に設置した。
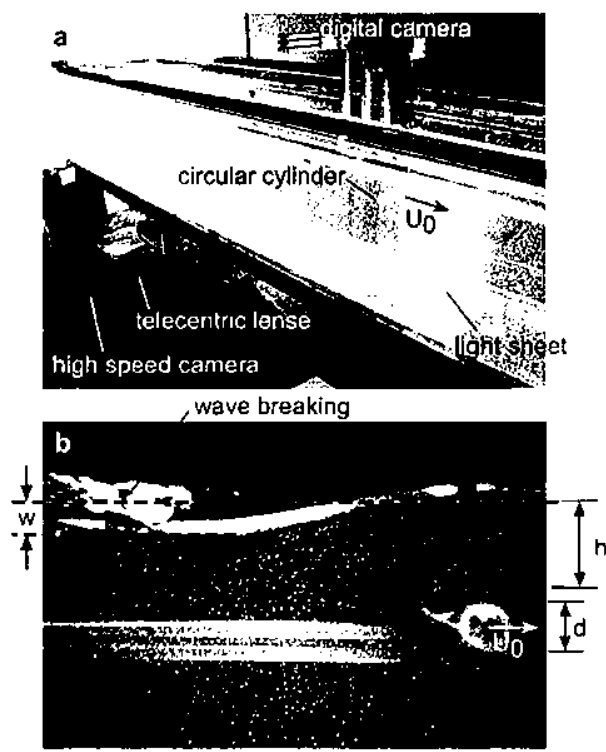

Fig.1 (a) Experimental setup, (b) close-up view of the flow around a circular cylinder. 


\section{2 実験パラメータ}

境界のない流体中を一定速度 $\mathrm{U}_{0}$ で運動する円柱周り の流れは古典的な問題として昔から数多くの研究がなさ れており，一般にその振る舞いは $\operatorname{Re}$ 数 $(\operatorname{Re}(\mathrm{d})=$ $\left.\mathrm{U}_{0} \mathrm{~d} / v\right)$ によって整理されている ${ }^{1)}$. 本研究のように, それに自由境界面が 1 つ増えた場合には，無次元深さ $(\mathrm{a}=\mathrm{h} / \mathrm{d})$ や $\mathrm{Fr}_{\mathrm{r}}$ 数 $\left(\mathrm{Fr}(\mathrm{d})=\left(\mathrm{U}_{0}{ }^{2} / \mathrm{gd}\right)^{1 / 2}, \operatorname{Fr}(\mathrm{h})=\left(\mathrm{U}_{0}{ }^{2} / \mathrm{gh}\right)^{1 / 2}\right)$ といった無次元数を考慮する必要がある ${ }^{2.3)}$. 自由境界 を含む円柱周りの流れに関する研究は比較的少なく ${ }^{2,3)}$, 特に高 Re 数・高 Fr 数領域における現象の理解はあま り進んでいない，そこで本実験では， $2 \times 10^{3}<\operatorname{Re}(\mathrm{d})<$ $2 \times 10^{4}, \quad 0.14<\mathrm{a}<2.41,0.21<\mathrm{Fr}(\mathrm{d})<2.2,0.14<$ $\operatorname{Fr}(\mathrm{h})<5.85$ の広いパラメー夕領域で実験を行った.
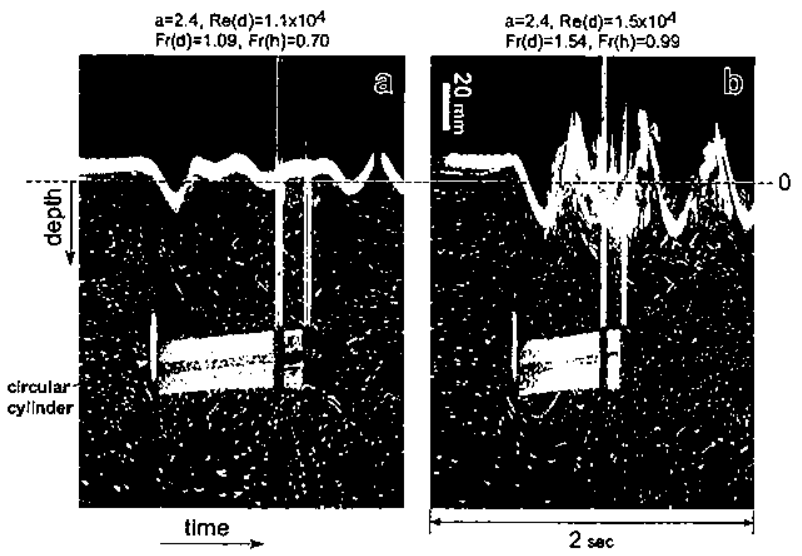

Fig.2 Spatio-temporal distribution of the airwater interface at the position of the high speed camera. (a) small Re and Fr, (b) large Re and Fr.

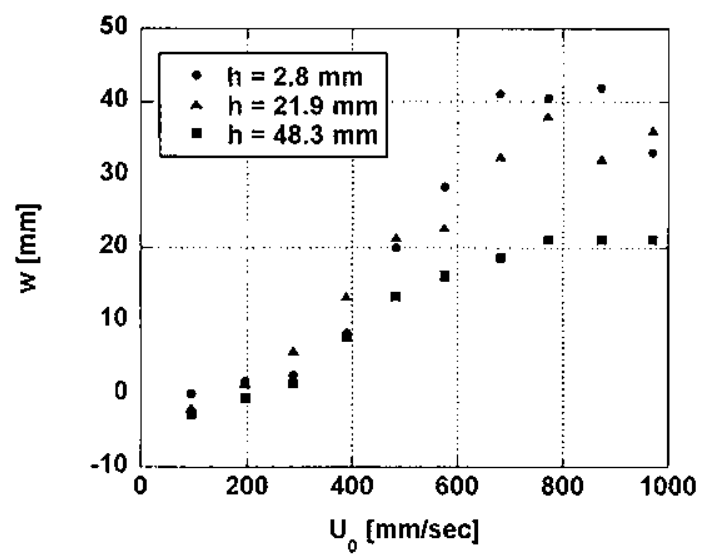

Fig.3 Maximum depression of the air-water interface $(w)$ as a function of $U_{0}$.

\section{3. 実験結果}

Fig. 2 は, 高速度カメラで得られた画像の中央䋛 1 列 （幅 1 pix）を時系列で並べた図の例である、低 $R e$ 数・ 低 Fr 数領域（Fig. 2a）では気液界面の変形量が小さく,
空気が水中に巻き込まれることはなかった。しかしなが ら，高 Re 数・高 Fr 数領域 (Fig. 2b) では, 円柱背後の 波が高くなり過ぎて崩れる現象（wave breaking）が起 こった：その際，空気が水中に取り込まれ，気泡が生成 された. Fig. 2b の画像中，明るく輝いている部分は，生 成された気泡からの强い散乱光である。

Fig. 3 は, Fig. 2 を用いて円柱通過後の最大窪み量 （w）を計測した結果である. 円柱の進行速度 $\mathrm{U}_{0}$ が大

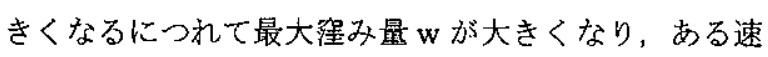
度以上になると一定の值を取るように見える. 円柱の上 から撮影した画像によると、この遷移は波が崩れて気泡 が生成され始める領域と一致しているようである。

Fig. 4 は， Re(d)と Fr(h)を用いた気泡の生成条件に関 する相図である、データ数が少ないものの,この図から 気泡の生成領域と非生成領域の住み分けが確認できる.

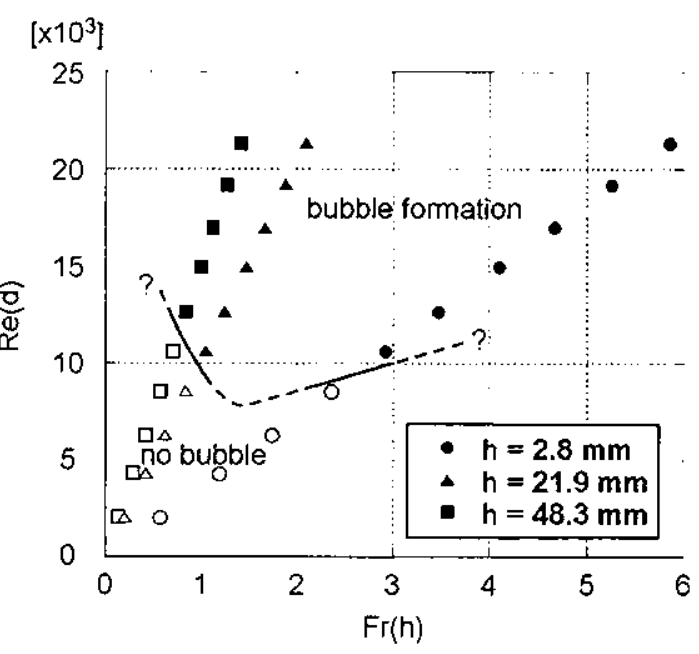

Fig.4 Regime diagram of bubble formation by a cylinder moving beneath the air-water interface. Open and closed symbols show non-existence and existence of bubble formation, respectively.

\section{4. 結論}

気液界面直下を水平方向に運動する円柱周りの流れと 円柱背後の界面の最大変形量を調べるための流体実験を 行った. Re 数・Fr 数が大きい場合, 円柱背後の波が崩 れ，それに伴って空気が水中に取り込まれ，気泡が生成 される、気泡生成の境界は，Re 数と Fr 数に依存する.

\section{参考文献}

1) Williamson, C.H.K. Vortex dynamics in the cylinder wake, Annu. Rev. Fluid Mech., 28 (1996) pp. 477-539.

2) Sheridan, J., Lin J. C., and Rockwell, D.: Flow past a cylinder close to a free surface, J. Fluid Mech., 330 (1997) pp. 1-30.

3) Reichl, P., Hourigan, K., and Thompson, M.C.: Flow past a cylinder close to a free surface, J. Fluid Mech., $533(2005)$ pp. 269-296. 